random amplitude and phase screens and then goes on to examine propagation through thick layers of turbulent material, typically the atmosphere. The discussion concludes with an analysis of stellar speckle interferometry. In the final chapter, he presents the semi-classical theory of photodetection, including photo-counting statistics, the notion of degeneracy parameter, and noise limitations in various kinds of interferometry.

The text is clearly and interestingly written, but one serious criticism remains (probably reflecting more on the status of optics in university physics curricula than on Professor Goodman): this is not a complete optics course, so students must presumably attend others in which they could reasonably be expected to learn about partial coherence and its propagation. Such topics could therefore have been covered much more concisely, leaving space to deal thoroughly with material more likely to be new: the phase problem, super-resolution, and the host of statistic- al methods and notions used in image processing.

For physicists, then, Statistical Optics will be welcome as a guide to the parts of statistics needed in optics, but it does not go deep enough into the various applications for the student who plans to make optics his career, or at least the subject of his $\mathrm{PhD}$ research. For the electrical engineering community, however (and Professor Goodman's chair is in this subject), the book probably provides a useful initiation into the optical world for those whose preoccupations bring them into contact with the topics covered but who do not need to go into them too deeply. There is thus still room for a book in which the author assumes that his readers have mastered the statistics in this book, or in Frieden's, and are now ready for a thorough examination of statistical optics.

P. W. Hawkes is Maitre de Recherche at the Laboratoire d'Optique Electronique du CNRS BP 4347, F-31055 Toulouse Cedex, France.

\section{A life in theory}

\section{Esther R. Phillips}

The Mathematics of Sonya Kovalevskaya. By Roger Cooke. Springer-Verlag:1985. Pp.234. DM96, \$29.80.

SONYA Vasilievna Kovalevskaya (18501891) was a mathematician, poet, novelist, dramatist, political tract writer and, some would add, revolutionary. She embraced the nihilism of the 1860 s, with its optimistic, perhaps naive, faith in the power of science and reason to establish a better society, and set out, against great odds, to obtain the university education that would enable her to take part in the building of a new society.

In the course of her turbulent and sometimes melodramatic life, Kovalevskaya contracted a fictitious marriage (1868) which permitted her, along with her sister and friends, to travel abroad to receive the university education denied them in Russia. Barred from attending classes at the University of Berlin (as were all women), she persuaded Karl Weierstrass, one of the leading mathematicians of his time, to give her private lessons covering the material he presented in his university lectures. Her studies were abruptly interrupted in 1871 when she journeyed to be at the side of her sister, an active participant in the short-lived Paris Commune; here Kovalevskaya served as a nurse for five weeks.

Returning to Berlin she resumed her studies, and under Weierstrass's direction she received a doctorate in mathematics (the first awarded to a woman) in 1875. A five-year break from mathematics followed, during which she returned to Russia, had a child, engaged in disastrous real estate speculations, wrote several nonmathematical works and plunged into a frenetic social life in Petersburg. With the help of Weierstrass and G. Mittag-Leffler (also a former student of Weierstrass) she obtained a position (the first woman to do so) at the University of Stockholm, where, in 1889 , she was appointed professor for life. The previous year she had received the Bordin Prize of the Paris Academy of Sciences for her memoir on the rotation of rigid bodies.

Finally, in 1889 she was elected to the Petersburg Academy of Sciences (again, a first for a woman) as corresponding member. At the time of her sudden and untimely death in 1891, Kovalevskaya was at the height of her career - an "international celebrity", as Roger Cooke describes her (p.116).

In the book Cooke has provided a complete account of Kovalevskaya's work and a sympathetic, but not adulatory, assessment of it. Although numerous articles with biographical details have been published, there is only one full length biography in English (with almost no discussion of her mathematics), A.H. Koblitz's A Convergence of Lives (Birkhäuser, 1983).

By describing in some detail the investigations of her predecessors, the author has quite correctly presented Kovalevskaya's achievements in a proper historical context. For example, in discussing one of her best known results usually referred to as the CauchyKovalevskaya theorem - he distinguishes between the modern textbook version (that it is an existence and uniqueness proof) and what Kovalevskaya, working within the Weierstrassian tradition, had set out to do, namely to demonstrate how analytic functions could be defined by means of formal power series arising as solutions of partial differential equations. Cooke has widely supplemented the description of Kovalevskaya's results with appendices containing technical details and has provided suitable "translations" of the original results into contemporary language. However, despite the author's intention to write a book for nonspecialists (p.vii), I do not believe that the more technical sections will be accessible to readers who have not (at the very least) completed a course in complex function theory.

Today Kovalevskaya's achievements have taken on something of a mythical quality, and she has been elevated to a prominent position in the feminist pantheon. Thus a valuable part of this volume contains assessments of her work made by her contemporaries, H. Poincaré, A.A. Markov, V. Volterra, G. Mittag-Leffler and (in 1926) F. Klein. Cooke generally concurs and concludes that she was

a competent, creative mathematician who produced some valuable work and a few works of minor importance, making an occasional mistake in the process ... she would not seem quite so remarkable if she had lived a century later, when no one is surprised to see a competent woman mathematician [pp.178-179].

Esther R. Phillips is Professor in the Department of Mathematics and Computer Science at Lehman College, The City University of New York, Bedford Park Boulevard West, Bronx. New York 10468, USA.
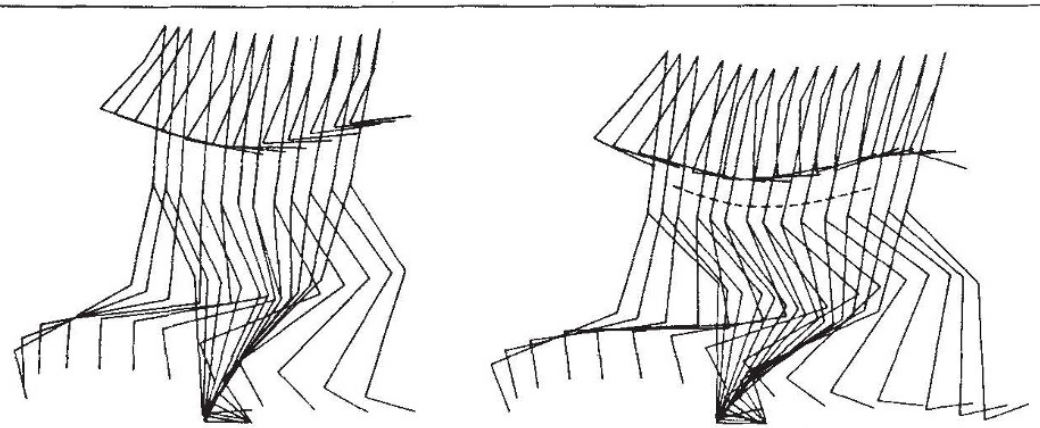

Run to ground - stick figures traced from movie films showing normal running (left), and a perturbed form of running (Groucho running) in which the aerial phase of the gait and the bumpiness of the ride are reduced but the metabolic cost is higher. The illustration is taken from a paper in Design and Performance of Muscular Systems, recently published by The Company of Biologists. Distributor is The Biochemical Society, price is $£ 25, \$ 60$. 